\title{
Journal Ranking Based on Publication Difficulty Factors (JRpDF): A Proposed Mathematical Algorithm
}

\author{
https://doi.org/10.3991/ijet.v16i14.22837 \\ Hussein M. Al-Yaseen \\ Al-Ahliyya Amman University, Amman, Jordan \\ hyaseeneammanu.edu.jo
}

\begin{abstract}
Academic publishing appears to be the most important key of the academic functions. Selecting the right journal to publish is a challenge to academics. Yet, there is inadequate knowledge about a model specifically directed at the topic of the journal selection process with a mathematical certainty. The objectives of this research are: to identify the main factors that researchers consider when selecting an academic journal for submitting a manuscript, and, to develop a mathematical algorithm of journal selection that provide the best journal choice with a mathematical certainty based on difficulty of each factor.

Quantitative research through questionnaires has been applied as an appropriate instrument base to address the researcher's identification of the factors that should be considered when selecting a journal for submission a manuscript. Questionnaire developed and emailed to academics in 31 public and private universities in the developing countries.

Academics in the sample reported that the most important publication difficulty factors were publishing in reputable journals that are indexed and abstracted in well-known databases, and publishing in a journal that has an impact factor. However, the most least publication difficulty factors were found to be: number of issues per year of the journal and if the journal is an open access or with subscription. The proposed mathematical algorithm (equation) and a graphical model of journal's publication difficulty factors were developed and tested on a sample of journals.
\end{abstract}

Keywords - Journal ranking, Publication, Mathematical Algorithm, Academic Research, Promotion, Quantitative, Developing Countries

\section{Introduction}

Academic sector in developed and developing world is relatively large, and very competitive due to the growth of academic education institutes (public and private) and due to the expansion of scholars, there are 550 universities in Middle East and more than 320000 academics [1]. The main functions of an academics in higher education institutes are: academic research, teaching and learning, and community engagement and services $[2,3,4]$. Academic research appears to be a key of the three academic functions. A very competitive academic environment will motivate and create high pressure on scholars to produce academic research. Scholars publish their results in a 
range of forms, such as: book reviews, conference proceedings, books, reviews, preprints, working papers, invited chapters, dictionaries and encyclopedias, scholarly journals.

Academic promotion is one of the most important challenge to academics and based on a range of criteria, such as: excellence in teaching and learning; reputable publications; research grants and innovation; postgraduate supervision; recognition and leadership; social and community services; consultancy to the government and industries; and administrative roles in the university [5]. Academic publications are measured based on the quantity and quality of publications (how prestigious the journals academics were published in), reputable peer-reviewed journals are those that are indexed and abstracted in well-known databases, such as: Arts \& Humanities Citation Index (Web of Science); Science Citation Index Expanded (Web of Science); Social Science Citation Index (Web of Science); Excellence in Research for Australia (ERA); Association of Business Schools (ABS); SCOPUS, to mention but a few, or if the journal has a high Impact Factor (IF).

The process of selecting an appropriate journal is a challenging process to authors and can easily take months, the proper selection of an academic journal is critical to publishing success. Yet, one research paper has been found specifically directed at the topic of developing a model or framework of the journal selection process [6]. [6], built their model on prior research from different disciplines, their results found about that there are five categories represent the major considerations an author should deliberate when selecting a journal for publication, these are: likelihood of acceptance, credibility and prestige of the journal, potential impact of the manuscript (visibility), timeline from submission to publication, and philosophical and ethical issues. Then, the five categories combined into a graphical model of the journal selection process. Researchers can get benefit from the model, the graphical model provides new researchers with understanding into how journal selection decision balance three categories (likelihood of timely acceptance, potential article impact, and philosophical and ethical considerations). Though, the model has limitations, researchers lack the knowledge required to precisely answer each question proposed by the model, furthermore, the model does not provide the best journal choice with a mathematical certainty. This shapes a motivation for researchers to develop a model that can provide the best selection of a journal with high level of certainty to help authors in the selection process.

\section{Theoretical Background}

This section provides a background of academic promotion criteria in developing countries, further it describes publishing process and its main stages.

\subsection{Academic promotion criteria}

This section briefly describes the main criteria for the promotion in general with the concentration on 'publication and writing' criterion in particular. 
Criterion 1: Teaching and learning: Teaching and learning criterion can be evaluated based on (role as academic advisory, number of credits for the courses, the number of courses taught, number of students per course, involvement in undergraduate student supervisory duties and curricula, the evaluation of teaching quality and performance by students is also considered, and other academic workloads).

Criterion 2: Postgraduate supervision: Postgraduate supervision criterion can be evaluated based on (the involvement in the Master and $\mathrm{PhD}$ programmes, number of students under supervision, number of graduated students on time, and the supervisory role (e.g. if supervisor, co-supervisor or a member in a supervisory panel)).

Criterion 3: Administrative roles: Administrative roles criterion can be evaluated based on the contribution to the university and it refers to the involvement, participation and responsibilities in the university. The contribution is measured based on the roles held at the level of university management and leadership, such as: (vice chancellor, deputy vice chancellor, faculty dean, director, head of department, head of programme).

Criterion 4: Academic recognition and leadership: Academic recognition criterion can be evaluated based on the level of respect received by an academic from academic community national or international, such as: (reviewer of manuscripts, journal articles and papers; appointments as examiners of theses; evaluator in a promotion processes, external examiner; invited as a keynote speaker at conferences; receiving awards (teaching and research awards, or other awards for academic and research excellence); visiting professor; editing academic journals or books).

Criterion 5: Consultancy: Consultancy criterion can be evaluated based on the consultancy provided to agencies (governmental or non-governmental), or industries, research collaborations, contract services, industrial links and joint projects.

Criterion 6: Community services: Community services criterion can be evaluated based on the involvement and participation in providing services to the community, such as: serving as a member of committees (nationally or internationally), voluntary services, participating in community development programmes.

Criterion 7: Research and grants: Research and grants criterion can be evaluated based on number and amount of research grants, sources of research grants, research projects, research projects role (main researcher, co-researcher), research projects impact.

Criterion 8: Publication: The Ministry of Higher Education (MoHE) in developing countries is responsible for setting a regulations and guidelines for the promotion process in the public and private universities, however, each university has the right to determine the quantity and quality of publication for each academic rank. Publication criterion can be evaluated based on quality and quantity of academic publications. Quality of publication includes papers in reputable journals, chapters in books, published books and proceedings. Reputable journals refer to those journals that are indexed and abstracted in well-known databases, such as (Thomson Reuters (ISI), SCOPUS, Association of Business Schools (ABS), Elsevier, Excellence in Research for Australia (ERA) etc.). Further, the journals have an impact factor (IF). It is acknowledged that publications in reputable journals are the most important forms of academic promotion that receive the most notice from promotion committees $[7,8]$. 


\subsection{Publishing process}

The process of academic publishing is divided into three distinct phases: 1) finding an appropriate journal, 2) submit a manuscript to a publisher, and 3) peer-review process.

After having a complete manuscript written, the author starts the process of finding the appropriate journal. Journal selection decision is the most challenging decision as the accurate selection is very critical to publishing success process. There are different possibilities in how authors select academic journal for their publication, most of the literature suggest similar ideas about selecting academic journal for publication, such as: "ask your colleagues" or "consult a librarian", while, other authors try to search the Internet to select from a possible journal lists (e.g.: Google; Ulrich's Periodicals Directory; Directory of Open Access Journals; Thomson Reuters (ISI); Excellence in Research for Australia (ERA); SCOPUS etc.). Most of the databases offer a basic data about the journal that are included in their journal lists, such as: P-ISSN; E-ISSN; journal title; research area/field; journal's aims/scope; editor and editorial board; owner/publisher; impact factor, while other databases (e.g. Lamp's journal ranking site; AISNet site; Informing Science Institute) provide more information about the journals, such as: indexing/abstracting; acceptance rate, however, a few databases (e.g. Cabell's online directory) explains each journal's guidelines and the review process, Cabell's directory provide three categories of Difficulty Acceptance (Rigorous, Significantly Difficult, and Difficult) (https://www.cabells.com).

Most of the literature [such as: $9,10,11,12,13,14,15]$ attempt to provide guidance or questions that the authors need to ask when selecting a journal, such as: Is this journal peer-reviewed? Who is this journal's audience? Is this a prestigious journal? How long will it take to see your article in print? however, other researchers provide issues to be considered when selecting a journal, such as: audience; journal type; basic journal information; the impact, ranking and indexing status by citation databases; review process; article processing charge/fees.

The main problem is that there is inadequate knowledge about a model specifically directed at the topic of the journal selection process with a mathematical certainty. Therefore, the objectives of this research are threefold: firstly, to identify the main factors that an author or researchers consider when selecting an academic journal for submitting his/her manuscript. Secondly, to develop a mathematical algorithm of journal selection that provide the best journal choice with a mathematical certainty based on difficulty of each factor. Thirdly, test of the mathematical algorithm on a real data on a sample disciplines for applicability and reliability purposes for further amendments and improvements. To achieve the research objectives, the following research questions need to be answered by researchers, scholars, and librarians who are most involved with the process of selecting an appropriate journal for publications.

- What are the most important factors that researchers consider when selecting an academic journal when submitting a manuscript?

- What are the weight of each factor compared to other factors? 
The remainder of the research is structured as follows: section 3 identifies the research methodology and approach; section 4 presents the results and discussion and testing the mathematical algorithm; section 5 the conclusions, limitations and future work.

\section{$3 \quad$ Research Methodology and Approach}

To achieve the objectives of this research, which needed a high rate of respondents to enhance the validity and reliability in order to generalize the findings of this research, as suggested by the argument of $[16,17,3,18]$, we opted for quantitative research through questionnaires as an appropriate instrument $[19,20,21]$ base to address the researcher's identification of the factors that should be considered when selecting a journal for submission a manuscript $[22,12,23,24,25,26]$. The following section describes the process of questionnaire design, deployment, and analysis used. Figure 1 represents the sequential structure of the research phases.

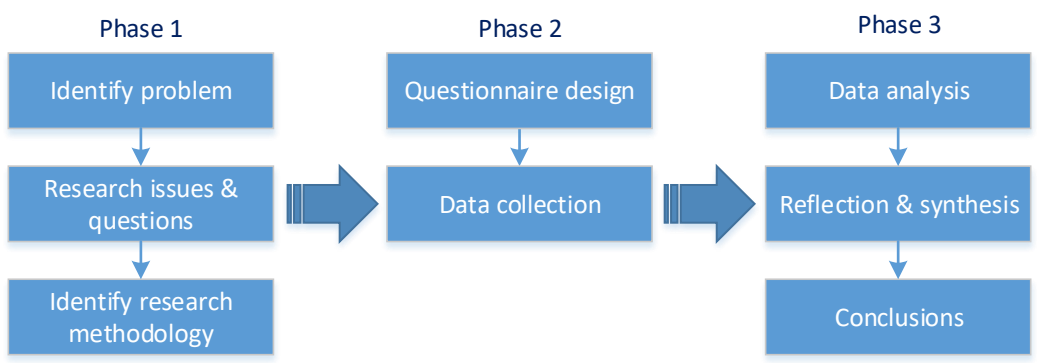

Fig. 1. Research phases

\subsection{Research phases}

Phase one reviews and document current literature of the main publication difficulty factors related to the selection of an academic journal. The main difficulty factors identified in the literature were then used to develop a questionnaire that aims to gather information about: Abstracting/ Indexing, Impact Factor, Acceptance rate / rejection rate, Number of issues per year, Lag time to publication, Open access / subscription, Article Processing Charge (APC), and other factors. The questionnaire is centred on gathering information on: the importance of publication difficulty factors, weighting each factor, sorting these factors so the mathematical algorithm can be developed, as well as, other information related to publication difficulty factors.

Phase two, the questionnaire developed in phase one were emailed and posted to 9300 academics in 31 public and private universities in the developing countries. The questionnaires were mailed to academics in different faculties that covered a variety of disciplines (such as: Agricultural; Biological Sciences; Arts and Humanities; Business; Engineering; Computer Science; Mathematics etc.).

Phase three represents data analysis, results and discussion, limitations and possible future work. Of the 9300 questionnaires posted, 34\% responses (3162) were received; 
$3 \%$ (94) were returned unanswered or incomplete. The latter category was ignored making the final number of usable responses 3068, giving a response rate of $31 \%$. Data were analysed using a combination of the parametric statistical methods and descriptive analysis.

\section{$4 \quad$ Results and Discussion}

The objectives of this project were: identifying publication difficulty factors that researchers consider when selecting an academic journal for submitting a research; assign a weight for each publication difficulty factor; develop a mathematical algorithm (equation) for journal selection that provide a better journal choice; and then test the mathematical algorithm for applicability and reliability purposes on different disciplines.

\subsection{Publication difficulty factors}

When the participants were asked about the importance of the publication difficulty factors; most of the academics in the sample reported that the most important publication difficulty factors were publishing in reputable journals that are indexed and abstracted in well-known databases, and the most important databases were found to be (Clarivate Analytics formerly Thomson Reuters (ISI), Excellence in Research for Australia (ERA), Association of Business Schools (ABS), SCOPUS, Elsevier. Furthermore, the second important publication difficulty factor was publishing in a journal that has an impact factor. However, the most least publication difficulty factors were found to be: number of issues per year of the journal and if the journal is an open access or with subscription.

\subsection{Publication difficulty factors weight}

When we asked the participants to give a weight for each proposed publication difficulty factor in the questionnaire, results showed that the highest weight has been assigned to indexing/abstracting in Clarivate Analytics formerly Thomson Reuters (ISI) $(25 \%)$ and the second highest weight has been assigned to the impact factor as a publication difficulty factor $(25 \%),(15 \%)$ if the journal is indexed or listed in ERA, (15\%) if the journal is indexed in ABS, (10\%) if the journal is indexed in SCOPUS, and (10\%) if the journal is indexed in Elsevier as shown in Table 1. 
Table 1. Publication difficulty factors and their weight

\begin{tabular}{|c|c|c|c|c|}
\hline \# & $\begin{array}{c}\text { Publication difficulty } \\
\text { factor }\end{array}$ & Weight & Publication difficulty sub-factor & Sub-factor weight \\
\hline \multirow{5}{*}{1} & \multirow{5}{*}{$\begin{array}{l}\text { Journal is Indexed in well- } \\
\text { known databases }\end{array}$} & \multirow{5}{*}{$75 \%$} & Thomson Reuters ISI & 25 points \\
\hline & & & $\begin{array}{l}\text { Excellence in Research for Australia } \\
\text { (ERA) }\end{array}$ & 15 points \\
\hline & & & $\begin{array}{l}\text { Association of Business Schools } \\
\text { (ABS) }\end{array}$ & 15 points \\
\hline & & & SCOPUS & 10 points \\
\hline & & & Elsevier & 10 points \\
\hline \multirow{3}{*}{2} & \multirow{3}{*}{$\begin{array}{l}\text { Journal has an impact fac- } \\
\text { tor }\end{array}$} & \multirow{3}{*}{$25 \%$} & IF (Thomson Reuters) & \multirow{3}{*}{25 points } \\
\hline & & & SNIP/IPP & \\
\hline & & & SJR & \\
\hline & Total & $100 \%$ & & 100 points \\
\hline
\end{tabular}

\subsection{Proposed equation of publication difficulty factors}

As shown in Table 1, the two most important publication difficulty factors were (Abstracting/Indexing of the journal and the Impact Factor of the journal), however, the least important publication difficulty factors were (Acceptance rate / rejection rate, Number of issues / year, Lag time to publication, Open access / subscription, and Article Processing Charge (APC)), the least important publication difficulty factors can be excluded from the mathematical algorithm. The proposed equation of journal's publication difficulty factors can be created as the sum of two publication difficulty factors these are: (journal is indexed in well-known databases, journal has an impact factor) as shown in Figure 2 and Figure 3.

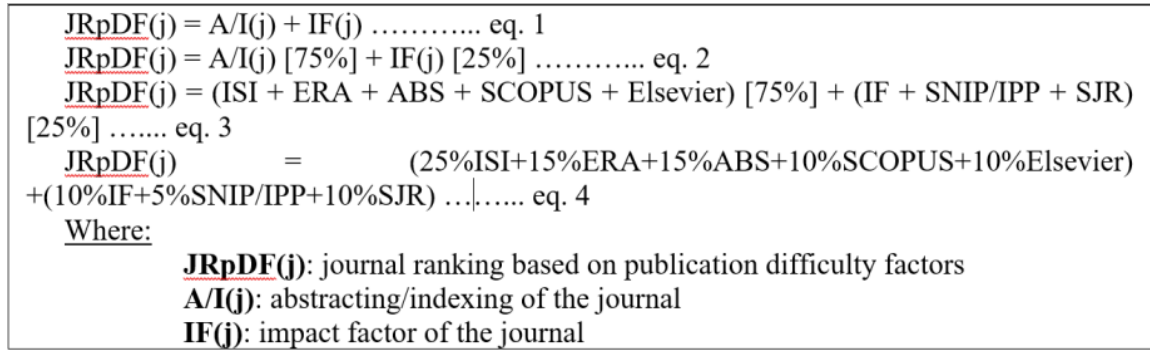

Fig. 2. Proposed mathematical algorithm of journal's rank based on publication difficulty factors 


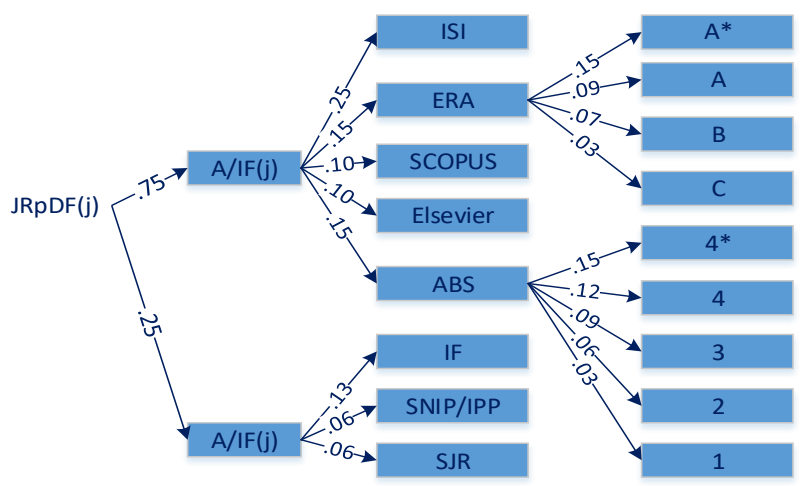

Fig. 3. Proposed mathematical algorithm of journal's rank based on publication difficulty factors

\subsection{Proposed graphical model of publication difficulty factors}

The two main publication difficulty factors can be reorganized in a two-dimensional graphical model, as shown in Figure 4, the first dimension is the journal impact factor, and the second dimension is journal abstracting/indexing. After applying the mathematical algorithm on the journals in the specified research field, it can be located using the model, as shown in Figure 4.

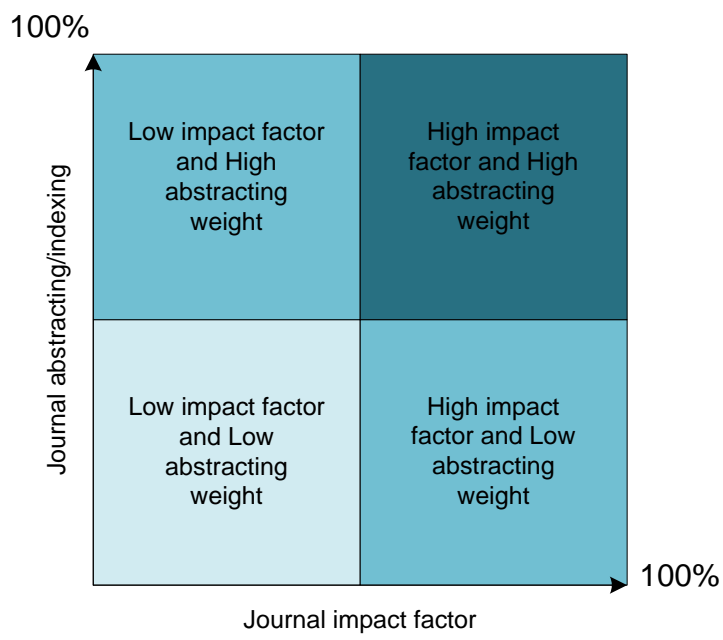

Fig. 4. Graphical model of journal's rank based on publication difficulty factors

The graphical model includes 4 quadrants, the upper right quadrant in Figure 4 represents those journals that have a high impact factor and a high abstracting and indexing weight, journals in this quadrant are most likely to have a lower probability of 
acceptance. The upper left quadrant represents those journals that have a high abstracting and indexing weight but low or moderate impact factor. The lower right quadrant represents those journals that have high impact factor and low or moderate abstracting and indexing weight. The lower left quadrant represents those journals that have low or moderate impact factor and low or moderate abstracting and indexing weight, journals in this quadrant are most likely to have a higher probability of acceptance.

\subsection{Testing the mathematical algorithm and graphical model}

In order to test the mathematical algorithm, a sample of 13 journals were selected from Accounting and Finance discipline, these journals were selected randomly as shown in Appendix 1 and Appendix 2. Appendix 1 represents the basic information about the journals, such as: ISSN, journal title, indexing in (Thomson Reuters ISI, ERA, ABS, SCOPUS, Elsevier); further, it includes (impact factor of the journal IF, SNIP, and SJR).

The weight of each journal's publication difficulty factors has been calculated based on equation 4 (see Figure 2). If the journal is indexed in (ISI) then we assign a (25 points) for this journal; if the journal is indexed in (ERA) then we assign a weight based on the journal's rank in ERA: if the journal's rank is $\left(\mathrm{A}^{*}\right)$ we assign a (15 points) to that journal, (rank $\mathrm{A}$, we assign 11 points; rank $\mathrm{B}$, we assign 7 points; rank $\mathrm{C}$, we assign 3 points) (as shown in Figure 2), if the journal is indexed in (ABS) then we assign a weight for each journal based on the journal's rank in ABS: if the journal's rank is $\left(4^{*}\right)$ we assign a ( 15 points) to that journal, (rank 4 , we assign 12 points; rank 3 , we assign 9 points; rank 2, we assign 6 points; rank 1, we assign 3 points) (as shown in Figure 2), if the journal is indexed in SCOPUS, we assign (10 points) for the journal, if the journal is indexed in Elsevier, then we assign (10 points) for the journal, too.

Figure 5 represents the journals under consideration, journal 2 and journal 12 have the least abstracting/indexing weight and impact factor as shown in the graphical model, however, journal 6 and journal 8 have the highest abstracting/indexing weight and impact factor. 


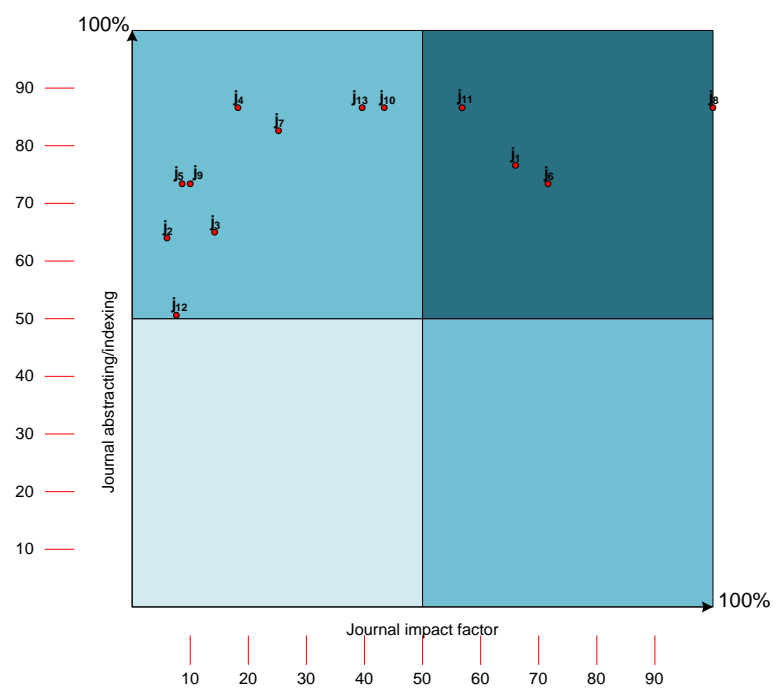

Fig. 5. Graphical model of journal's rank based on publication difficulty factors

\section{Conclusion}

The aims of this research were to identify different publication difficulty factors that researchers in developing countries consider when selecting a journal to which to submit their research, further, assign weight or value for each publication difficulty factor in attempt to develop a mathematical algorithm for journal selection. Based on the literature from variety of disciplines, a comprehensive list of publication difficulty factors was developed for journal selection considerations. Publication difficulty factors have been organized into six major considerations: (Abstracting/ indexing; impact factor; acceptance/ rejection rate; number of issues/years; lag time to publication; open access/ subscription -article processing charges (APC). A questionnaire was developed and emailed to most academics in public and private universities in the developing countries. It is concluded that the requirements and regulations of higher education in the Middle East countries are mainly comparable, this affect the result of the survey that showed the two most important considerations when selecting an academic journal were (Abstracting/Indexing of the journal and the Impact Factor of the journal). Based on the data analysis, a mathematical algorithm developed and tested on a small sample of journals, further, a graphical representation developed that assists researchers in comparing different journals. 


\subsection{Limitations and future work}

The proposed mathematical algorithm (equation) is an attempt to help researchers in the developing countries to make a decision when submitting their work. However, the proposed mathematical algorithm has some limitations. The proposed mathematical algorithm could be suitable for researchers in the developing countries higher education institutes and cannot be generalized to other developed countries due to respondents' profile. Furthermore, the proposed mathematical algorithm needs enormous data to be available on each journal in the same research field under consideration in order to assign a rank for each journal based on publication difficulty factors, some data is not available to researchers. Lack of information about each journal makes it difficult to apply the mathematical algorithm by researchers.

Future work could be a data collection process about the scholar journals in the different disciplines in the developing countries universities. More importantly, it is hoped that this research project has encouraged other scholars to follow-up this research that will help the PhD students and researchers make an informed decision to select an appropriate academic journal to publish their research findings as it is one of the critical steps in publicizing research results.

\section{$6 \quad$ References}

[1] Association of Arab Universities 2016. available at: http://aaru.ju.edu.jo/en/english/Lists/ Journals/Disp_Form.aspx?ID=1, accessed: May, 2016.

[2] Hajdarpasic, A., Brew, A. and Popenici, S. 2015. The contribution of academics' engagement in research to undergraduate education, Studies in Higher Education, 40 (4): 644-657. https://doi.org/10.1080/03075079.2013.842215

[3] Creswell, J. W. 2014. A concise introduction to mixed methods research, Sage Publications.

[4] Holland, B. A. 2016. Factors and strategies that influence faculty involvement in public service, Journal of Higher Education Outreach and Engagement, 20 (1): 63-72.

[5] Ministry of Higher Education and Scientific Research 2016. available at: www.mohe.gov.jo/en , accessed: June, 2016.

[6] Kinght, L. and Seinbach, T. 2008. Selecting an Appropriate Publication Outlet: A Comprehensive Model of Journal Selection Criteria for Researchers in a Broad Range of Academic Disciplines, International Journal of Doctoral Studies, 3: 59-79. https://doi.org/ $\underline{10.28945 / 3289}$

[7] Matar, N. A. (2017). Defining E-Learning Level of Use in Jordanian Universities Using CBAM Framework. iJET, 12(3), 142-153. https://doi.org/10.3991/ijet.v12i03.6497

[8] Matar, N., AlMalahmeh, T., Al-Adaileh, M., \& Al Jaghoub, S. (2020). Factors Affecting Behavioral Intentions towards Cloud Computing in the Workplace: A Case Analysis for Jordanian Universities. International Journal of Emerging Technologies in Learning (iJET), 15(16), 31-48. https://doi.org/10.3991/ijet.v15i16.14811

[9] Caligiuri, P. M. 1999. The ranking of scholarly journals in international human resource management, International Journal of Human Resource Management, 10 (3): 515-519. https://doi.org/10.1080/095851999340468

[10] Saha, S., Saint, S. and Christakis, D. A. 2003. Impact factor: a valid measure of journal quality? Journal of the Medical Library Association, 91 (1): 42. 
[11] Garfield, E. 2006. The history and meaning of the journal impact factor, Jama, 295(1): 9093. Available at http://jama.ama-assn.org/cgi/reprint/295/1/90, accessed: June, 2016. https://doi.org/10.1001/jama.295.1.90

[12] Serenko, A. and Bontis, N. 2013. Global ranking of knowledge management and intellectual capital academic journals: 2013 update, Journal of Knowledge Management, 17 (2): 307 326. https://doi.org/10.1108/13673271311315231

[13] Zitt, M. and Small, H. 2008. Modifying the journal impact factor by fractional citation weighting: The audience factor, Journal of the American Society for Information Science and Technology, 59 (11): 1856-1860. https://doi.org/10.1002/asi.20880

[14] Sugimoto, C. R., Larivière, V., Ni, C. and Cronin, B. 2013. Journal acceptance rates: A cross-disciplinary analysis of variability and relationships with journal measures, Journal of Informetrics, 7 (4): 897-906. https://doi.org/10.1016/j.joi.2013.08.007

[15] Lamb, C. R. and Adams, C. A. 2015. Acceptance rates for manuscripts submitted to veterinary peer reviewed journals in 2012", Equine veterinary journal, 47 (6): 736-740. https://doi.org/10.1111/evj.12376

[16] Tashakkori, A. and Teddlie, C. (2003), "The past and the future of mixed methods research: from methodological triangulation to mixed methods designs", in Tashakkori, A. and Teddlie, C. (Eds), Handbook of Mixed Methods in Social and Behavioral Research, Sage, Thousand Oaks, CA. https://doi.org/10.4135/9781506335193

[17] Teddlie, C. and Tashakkori, A. (2009), Foundations of Mixed Methods Research: Integrating Quantitative and Qualitative Approaches in the Social and Behavioural Sciences, Sage Publications, Thousand Oaks, CA.

[18] Newcomer, K. E., Hatry, H. P. and Wholey, J. S. 2015. Handbook of practical program evaluation, John Wiley \& Sons. https://doi.org/10.1002/9781119171386

[19] Al-Yaseen, H., Eldabi, T. and Paul, R. 2004. A quantitative assessment of operational use evaluation of information technology: Benefits and barriers, Proceedings of the Americas Conference for Information Systems, NY, USA.

[20] Al-Jaghoub, S., Al-yaseen, H., Hourani, M., Al-Haddadeh, R. \& Salim, M. 2009. e-learning adoption in higher education in Jordon: vision, reality and change. European and Mediterranean Conference on Information Systems (EMCIS), Izmir, Turkey.

[21] Al-Soud, A., Al-Yaseen, H. and Al-Jaghoub, S. 2014. Jordan's e-Government at the crossroads, Transforming Government: People, Process and Policy (TG:PPP), 8 (4): 597-619. https://doi.org/10.1108/tg-10-2013-0043

[22] Rafols, I., Leydesdorff, L., O'Hare, A., Nightingale, P. and Stirling, A. 2012. How journal rankings can suppress interdisciplinary research: A comparison between innovation studies and business \& management, Research Policy, 41 (7): 1262-1282. https://doi.org/10.1016/ j.respol.2012.03.015

[23] Ho, R. C. M., Mak, K. K., Tao, R., Lu, Y., Day, J. R. and Pan, F. 2013. Views on the peer review system of biomedical journals: an online survey of academics from high-ranking universities, BMC medical research methodology, 13 (1): 1. https://doi.org/10.1186/1471$\underline{2288-13-74}$

[24] Hsu, W. C., Tsai, C. F. and Li, J. H. 2015. A hybrid indicator for journal ranking: An example from the field of Health Care Sciences and Services, Online Information Review, 39 (7): 858-869. https://doi.org/10.1108/oir-11-2014-0277

[25] Carraher, S. M. and Paridon, T. J. 2015. Entrepreneurship journal rankings across the discipline, Journal of Small Business Strategy, 19 (2): 89-98.

[26] Guo, H., Wang, B., Qiao, X. and Liu, R. 2016. A review of studies on citations and journal ranking in finance, Managerial Finance, 42 (4): 303-311. https://doi.org/10.1108/mf-04$\underline{2015-0123}$ 


\section{Author}

Professor Hussein Al-Yaseen completed a PhD in Information Technology Evaluation from Brunel University London. Started academic career in Department of Computer Science at Al-Ahliyya Amman University. Moved to Business School in 2006 as a Head of MIS Department, he is teaching (delivering successful projects and research methods for business) in Edinburgh Business School since 2011. Then, as a Business School Dean for 5 years. In 2015 become a full professor, and Dean of Scientific Research and Dean of Postgraduate Studies for 2 years.

Article submitted 2021-03-22. Resubmitted 2021-04-25. Final acceptance 2021-04-26. Final version published as submitted by the authors. 